\title{
Enhancing Artificial Intelligence with Indigenous Wisdom
}

\author{
Deborah H. Williams ${ }^{1,2}$, Gerhard P. Shipley³ \\ ${ }^{1}$ Department of Environmental Science, Johnson County Community College, Overland Park, Kansas, USA \\ ${ }^{2}$ Department of Anthropology, University of Kansas, Lawrence, Kansas, USA \\ ${ }^{3}$ Unaffiliated, Lawrence, Kansas, USA \\ Email: Research_Studies@outlook.com
}

How to cite this paper: Williams, D. H., \& Shipley, G. P. (2021). Enhancing Artificial Intelligence with Indigenous Wisdom. Open Journal of Philosophy, 11, 43-58. https://doi.org/ 10.4236/ojpp.2021.111005

Received: November 19, 2020

Accepted: January 29, 2021

Published: February 1, 2021

Copyright (C) 2021 by author(s) and Scientific Research Publishing Inc.

This work is licensed under the Creative Commons Attribution International License (CC BY 4.0).

http://creativecommons.org/licenses/by/4.0/

(c) (i) Open Access

\begin{abstract}
The current "narrow" or "weak" form of artificial intelligence is, by itself, fundamentally a data analysis tool that does nothing more or less than its programming instructs it to do. It has no values or goals of its own, it simply follows the values and pursues the goals provided to it by its programmers. Artificial wisdom has the potential to make artificial intelligence a better tool and eventually perhaps more than a tool, but at least for now artificial wisdom must also be programmed and therefore similarly reflects only the wisdom of its programmers. Artificial intelligence, with its reductionistic ontology of data and its contrived epistemology of algorithms, is the quintessential product of the Western scientific worldview, and the development and application of artificial intelligence and discussions of artificial wisdom still largely reflect that one, narrow worldview. Artificial wisdom would greatly benefit from incorporating elements of non-Western worldviews, particularly the metaphysically inclusive Indigenous worldview. For example, the Navajo concept of hozho involves the normative values and goals of harmony, balance, interrelatedness, and connectedness. Hozho and other Indigenous concepts are potentially paradigm-shifting additions to artificial wisdom and could greatly enhance the usefulness of and overall benefit from applications of artificial intelligence.
\end{abstract}

\section{Keywords}

Artificial Intelligence, Artificial Wisdom, Western Scientific Worldview, Indigenous Wisdom, Indigenous Worldview, Navajo Philosophy, Hozho

\section{Introduction}

"Knowledge without wisdom is a load of books on the back of an ass" (Japanese proverb).

Artificial intelligence (AI) in one form or another may soon be ubiquitous in both developed and developing societies. As a category, AI encompasses a variety of technologies which model human learning and decision-making behaviors. As yet, none of these technologies exhibit even animal-like consciousness and all are 
far from transcending their programming to achieve the emergent properties of the beings they attempt to model. The current "narrow" or "weak" AI is, by itself, fundamentally a data analysis tool (i.e., a means to an end) that does nothing more or less than its programming instructs it to do. It has no values or goals of its own, it simply follows the values and pursues the goals provided to it by its programmers. We have only begun to consider artificial wisdom (AW) as an essential complement with the potential to make AI a better tool and eventually perhaps more than a tool (i.e., an end in itself). At least for now, however, AW must also be programmed and therefore similarly reflects only the wisdom of its programmers.

Value judgments about the potential positive and negative effects of AI, both generally and with regard to specific applications, necessarily reflect the perspectives of particular worldviews. Worldviews are defined by ontological, epistemological, and analytical positions (Shipley \& Williams 2019), and therefore shape how we engage in our lived experiences, including informing our concepts of, relations between, and rights and obligations toward "self" and "other." As a concept and in its actual implementations, AI reflects the particular values and ideals of the Western scientific worldview, and as such arguably is more properly referred to as "artificial Western ethno-intelligence." AI has no normative ability of its own, it does not feel joy, guilt, or remorse and is wholly unable to care about the overall consequences of its actions or the individual persons affected by those actions. If AI operation is guided by any normative values at all, they are the values of programmers trained and working within the paradigm of the Western scientific worldview, and are based on a reductionistic ontology of data and a contrived epistemology of algorithms concerned with maximizing the efficiency with which tasks are accomplished and not the morality of the tasks themselves. Even then, AI can only follow normative rules that can be expressed and evaluated in quantitative terms.

Notions of wisdom are also products of worldviews, and even less work has been done to examine AW from the perspective of alternative worldviews, such as the metaphysically inclusive Indigenous worldview. While AI itself cannot be made to account for non-quantitatively expressible metaphysical considerations, its existence and function can be evaluated from and guided by a metaphysically inclusive perspective. In this paper, we examine current conceptions of AI and $\mathrm{AW}$, and we explore the possibility of incorporating wisdom from the Indigenous metaphysically inclusive worldview into AW, such as the Navajo concept of hozho.

\section{Intelligence and Artificial Intelligence}

"The world is one big data problem" (McLaughlin, 2012).

As with many of our most basic concepts, there is no one accepted definition of "intelligence." Definitions range from, for example, colloquialisms (e.g., learning, good sense) that add little and beg for their own definitions, to mathematical formulations so far removed from common understanding as to be effectively irrele- 
vant. "Most psychologists define intelligence as a very general capability that, among other things, involves the ability to reason, plan, solve problems, think abstractly, understand complex ideas, learn quickly, and learn from experience" (Wang \& Zheng, 2012: p. 64; see also Grieg \& Zimbardo, 2003). For this paper, we operationally define "intelligence" as the general ability to understand relevant information and apply that understanding to achieve a goal. We include the requirement for application in acknowledgement of the concern of behaviorists that unobservable mental phenomenon, such as understanding, can only be confirmed when manifested through observable behavior.

In its broadest sense, "artificial intelligence" can be defined as intelligence displayed by artificially constructed machines, in contrast to "natural intelligence" which is displayed by naturally occurring organisms. Computer science generally defines AI as "intelligent agents" which are devices that sense their environments and act to maximize the likelihood of achieving their goals (Poole et al., 1998; Russell \& Norvig, 2003; Legg \& Hutter, 2007). A more elaborate definition characterizes AI as "a system's ability to correctly interpret external data, to learn from such data, and to use those learnings to achieve specific goals and tasks through flexible adaptation" (Kaplan \& Haenlein, 2019: p. 15). According to Russell, Dewey, and Tegmark (2015: p. 105-106), in the context of modern AI research, "the criterion for intelligence is related to statistical and economic notions of rationality - colloquially, the ability to make good decisions, plans, or inferences," with the goal being to produce "economically valuable technologies." They argued that given that the societal impact of AI is certain to increase, and given that the focus has been on "techniques that are neutral with respect to purpose," the focus should shift to "maximizing the societal benefit of AI" (Russell et al., 2015: p. 106). To that end, research priorities should include optimizing economic impact, addressing legal and ethical issues (e.g., legal liability for autonomous vehicles, the use of autonomous weapons, and impacts on privacy), and ensuring robust AI that does what we want it to do (Russell et al., 2015).

The large majority of such discussions implicitly assume a Western approach to normative concerns about what it means to maximize social benefit and whether and how AI ought to be used to do so. Perhaps this is to be expected given the assumption that $\mathrm{AI}$ is to be a mere tool for achieving the goals we set for it, i.e., for doing what we want it to do. For example, if we decide that strip-mining or clear-cutting an area is desirable and set AI to the task of efficiently accomplishing that goal, we do not want the AI itself to apply an alternative approach and perhaps decide that the goal itself is unwise and refuse to perform. By focusing solely on accomplishing the task at hand and treating $\mathrm{AI}$ as a mere tool for accomplishing that task, the wisdom of the task can be blissfully ignored as a matter for philosophers and politicians or, in practical reality, corporate managers. After all, "[t]he computer science community who advocate AI seem to have little understanding of political theory [and] political economics outside the tired and outdated neoliberal paradigm" (Irwin \& White, 2019).

Currently, AI is limited to and excels at applications of mere intelligence as we 
have defined it. Davis postulated that AI will eventually be able to program computers better than humans do, and continually improve itself until it eventually creates artificial superintelligence (ASI) (Davis, 2019). "ASI will master the world of fact," [h]uman beings will be forced to cede the realms of description and prediction," and "[a]ll human participation in science will become a hobby" (Davis, 2019: p. 52). However, while it may become the master of descriptive facts, it likely will never make any progress in understanding normative values because it operates from a third-person, scientific perspective, and likely is incapable of ever developing a first person perspective (i.e., consciousness) necessary for making value judgments (Davis, 2019). Moral claims may be statements of preference, but disembodied preference does not exist - someone must have the preference (Davis, 2019). Even if moral claims are truth claims, they are subjective truth claims and so require subjectivity, i.e., first-person perspective, and the phenomena associated with the first-person perspective include consciousness, free will, and the unified self (Davis, 2019). "[T]he scientific worldview cannot offer an account of these phenomena capable of explaining and guiding first-person decision-making. Science and first-person decision-making, it seems, may be somewhat incompatible" (Davis, 2019: p. 54). In the context of law, for example, "even legal positivists generally acknowledge that moral judgments are often necessary in applying the law" (Davis, 2019: p. 55, emphasis in original). Further, to make legitimate and wise moral judgments one must be subject to the same judgments, but moral judgment applies only to conscious actors capable of moral agency (Davis, 2019).

So although there is concern that AI may one day become sufficiently intelligent to subjugate its creators, AI may likely never develop a sense of self and therefore never exhibit the full range of human cognition, including imagination, aesthetics, values, humor, and wisdom (Braga \& Logan, 2017). Thus, while AI is increasingly useful, "many aspects of the human experience that are associated uniquely with our species Homo sapiens ("wise humans") do not have analogues in the world of machine intelligence," and so the notion that humans will one day be fully surpassed by computers may be science fiction fantasy (Braga \& Logan, 2017). Nevertheless, "[AI] is a very useful tool for elites, whether governments or corporations ... it is another powerful weapon in the history of late capitalism and it is often being used in the service of exploitative extraction rather than the good of the ecosystem and communities" (Irwin \& White, 2019).

The remainder of this paper focuses on the importance of programmed AW both as an essential component of AI for evaluating the goals set for it and for choosing the most broadly acceptable "right way" of accomplishing those goals. Perhaps there will come a day when AI achieves personhood and gains the knowledge of good and evil for itself, and while we believe it is important that such an artificial person have a broadly based foundation of wisdom, that is not our current concern because an artificial person, like us natural persons, must ultimately make the journey toward wisdom and enlightenment on its own.

\section{Wisdom and Artificial Wisdom}


"We are drowning in information, while starving for wisdom" (Wilson, 1998: p. 294).

As with intelligence, there is also no one accepted definition for "wisdom," though we prefer "the right use of knowledge" because it evokes a broader normative goal-questioning aspect than mere goal-fulfilling intelligence. Developed and developing societies increasingly emphasize productivity and utility, which "has turned knowledge into nothing more than productive information" (Miguel, 2002: p. 239). The real project ought to be to produce information, which is used to produce knowledge, which is used to produce wisdom (Miguel, 2002). "[Intelligence] is about how to do something, what steps need to be taken in order to solve a specific problem ... Wisdom ... is about whether doing something or not makes sense" (Sevilla, 2013: p. 204). Kim and Mejia (2019) asserted that intelligence is concerned with finding the appropriate means, while wisdom is concerned with finding the right ends. Wang and Zheng (2012) defined wisdom as combining intelligence and morality both in gaining knowledge and in acting on gained knowledge. Baltes and Smith (2008: p. 56) noted that "[w]isdom is associated with good judgment and actions that contribute to living well." For this paper, we operationally characterize "wisdom" as the ability to determine whether a goal is ethical and which path to achieving a goal is ethically preferable.

Some have tried to quantify wisdom but it is a largely qualitative concept and requires answers and behaviors with depth that heavily depend on context and emotion (Sevilla, 2013: p. 204). As Weidenbener (2019: p. 21) noted, “wisdom seems to involve those aspects of human life where values, ethics, and decision-making goes beyond preprogrammed choices." Wisdom is not a matter of memorized replies to expected questions, "[a] wise statement alone is not an indication of wisdom" (Ardelt, 2004: p. 262), which seems to rule out symbolic approaches to artificial wisdom (Sevilla, 2013, but still arguing for a role for symbolism). Even if replies happen to be wise, they are not expressions of wisdom by the AI but rather expressions of the wisdom of the programmer. Sevilla (2013) argued that wisdom cannot be reduced to an algorithm for an expert system involving identifying and ordering rules of wisdom, relating them to actual scenarios, and monitoring these rules with metarules. Instead, wisdom is a characteristic of individuals and is deeply related to personal perspective. The acknowledged wise persons of history did not simply learn and apply the rules of their time better than others, but rather brought new insight and new approaches to situations and circumstances. According to Sternberg (2004: p. 287), "wisdom is the application of intelligence, creativity, and knowledge to the common good by balancing intrapersonal (one's own), interpersonal (others'), and extrapersonal (institutional or other larger) interests over the long and short terms, through the mediation of values."

Relatedly, Wu and Wu (2019: p. 5) characterized "big wisdom" as "[seeking] to synergize human intelligence and artificial intelligence for organizational activities in large environments where organizational/business intelligence and big data 
also play significant roles." Big wisdom involves human-machine synergism in an organizational context, in which human intelligence, AI, and organizational/business intelligence are integrated with big data in large environments and "big knowledge" is applied according to individual user's requirements while learning from user interactions (Wu \& Wu 2019). We interpret this concept of "big wisdom" as the employment of organizationally-specific knowledge to enhance the application of AI in achieving user-specific requirements within large organizations. Thus, in contrast to our goal of broad-based wisdom, big wisdom is narrower and more contextually specific and may not even fully reflect the notion of wisdom of a single worldview let alone multiple worldviews.

\section{Wisdom and Worldview}

"By three methods we may learn wisdom: First, by reflection, which is noblest; Second, by imitation, which is easiest; and third by experience, which is the bitterest." (Attributed to Confucius)

The well-known "is-ought" problem is reflected in the claim that there are no valid arguments from non-normative premises to a normative conclusion (Singer, 2015). In AI terms, while descriptive data is necessary to inform decisions, no amount of descriptive data, by itself, can determine what ought to be done. "[AI] appears to operate purely in the realm of the scientific world," and "morality is not directly discernable from the scientific perspective" (Davis, 2019: p. 53, 68, acknowledging that science can study the expressed opinions and observable conduct of moral agents, but cannot directly study the underlying ethics). Relatedly, data sets can be biased because data is a product of sociohistory (Weidenbener, 2019), so training an algorithm on a data set may only identify how the world has been and not how the world ought to be (Bell, 2017). Thus, even if normative judgments could be extracted from descriptive data, the former would only be as good as the latter, with no element of wisdom to correct for flawed data. It might be tempting for programmers who are aware of this to manipulate data sets in order to achieve equity (Weidenbener, 2019), but if the strength of AI is in finding patterns in data and we manipulate the data, then the overall effect may be impossible to predict.

AI programming is done by people, predominately men, operating within the Western scientific worldview, and their biases and notions of ethics and wisdom come through in their programming (Weidenbener, 2019). "Knowledge is about using information to achieve one's objectives and wisdom is the ability to choose objectives consistent with one's values," and at least for now, "[ $\mathrm{t}]$ he values of a computer are those of its programmers" (Braga \& Logan, 2017). Kim and Mejia (2019) identified two types of engineers: Those who think ethics is irrelevant to their work because they are not responsible for how their creations are used, and those who think that because they are very knowledgeable about engineering they are also very knowledgeable about ethics and able to make ethics decisions for everyone regarding their creations (Kim \& Mejia, 2019). The hypothetical "So- 
cratic engineer" would both accept that ethics is relevant to their work and admit that they have much to learn about ethics (Kim \& Mejia, 2019).

"Value alignment" seeks to ensure that AI incorporates values that are important to us. Kim and Mejia (2019) argued in favor of going beyond the conventional approach in which the principle of "do no harm" is a secondary constraint on design, and instead emphasizing that human well-being and human flourishing should be the primary goal of technology. Kim, Donaldson, and Hooker (2018) identified three types of value alignment: "Mimetic" which involves studying, determining, and imitating value-relevant human behavior; "anchored" which involves receiving and following normative rules regarding intrinsic values; and "hybrid" which involves some combination of the two. A problem with mimetic value alignment is that humans may be wrong about what ethics requires, and even when they are right they may choose to behave unethically, and so it is generally undesirable for AI to simply mimic human value-relevant behavior (Kim et al., 2018). A problem with anchored value alignment, which Kim, Donaldson, and Hooker (2018) only touch upon and suggest can be handled through a mimetic correction component, is that useful normative rules are not acultural. For example, "maximize happiness" is likely universal but not useful as it provides no guidance regarding the nature of happiness or how it is to be maximized. More specific normative rules, such as generalizability, respect for autonomy, and utility-maximization, are more useful but reflect a specific cultural concept of happiness. Given that "wisdom is fundamentally a cultural and collective product in which individuals participate" (Baltes \& Staudinger, 2000: p. 127), attempts to program AW will, without conscious effort to be more inclusive, introduce only the notions of ethics and wisdom which are peculiar to the Western worldview.

Wisdom is exalted in all cultures as a desired trait representing the ideal integration of knowledge and action, mind and virtue (Baltes \& Smith, 2008). According to Baltes and Smith, "[t]he substantial foundations for contemporary reflection about the nature and function of wisdom were laid by the ancient Greek philosophers" (Baltes \& Smith, 2008), but this fails to consider the perspectives and contributions of the many non-Western civilizations that came before and after the Greeks. Nevertheless, Baltes' "Berlin Paradigm combines a broad definition of wisdom as excellence in mind and virtue with a specific characterization of wisdom as an expert knowledge system dealing with the conduct and understanding of life," i.e., the "fundamental pragmatics of life" (Baltes \& Smith, 2008: p. 58). Of particular relevance to AI, intelligence is not the most powerful predictor of wisdom (Baltes \& Smith, 2008). More predictive are a combination of psychosocial characteristics and life history factors, including openness to experience, generativity, cognitive style, contact with excellent mentors, and some exposure to structured and critical life experiences (Baltes \& Smith, 2008). Further, people with more wisdom-related knowledge value the welfare of others more than their own happiness and are highly engaged in ensuring the well-being and interests of others (Baltes \& Smith, 2008). Again, however, it is not at all clear that this notion of wisdom is acultural or universal rather than the culturally-based opinions of 
those Baltes and his team have studied.

"Different cultures usually have diverse views on the notion of wisdom. While they share common views among them, each has its own unique insights" (Wang \& Zheng, 2012: p. 66). For example, Wang and Zheng (2012) compared and contrasted Western and Chinese notions of wisdom. The Chinese regard wisdom as the ability to understand human nature, and "[according to Mencius], a person will be regarded as wise, if he/she is good at understanding human nature and employing this knowledge for the well-being of the general public" (Wang \& Zheng, 2012: p. 66). In the Chinese tradition, the "wisdom of zuoren" (i.e., wisdom on how to become a virtuous person), is emphasized more than the "wisdom of zuoshi” (i.e., wisdom on how to do things practically) (Wang \& Zheng, 2012). Thus, moral wisdom is emphasized over natural wisdom in Chinese culture (Wang \& Zheng, 2012). While the Western tradition acknowledges both types of wisdom, it focuses more on the wisdom of zuoshi (Wang \& Zheng, 2012). "Emphasizing different elements of wisdom, Chinese and Western traditions should complement each other. Moral virtue should be given equal weight with intelligence. In this way, the appropriate account of wisdom can be guaranteed, and the insights from different traditions will be well preserved" (Wang \& Zheng, 2012: p. 66).

For another example, Ali (2011) discussed the role of Divine Islamic values in applications of AI, particularly with regard to the importance of representing Islamic values such as piety, obedience, and Halal and Haram in any AI which may make decisions for Islamic societies. "Secular and liberal values, if we consider them as values, do not serve the interests of Muslim communities ... If [AIs] are to make important decisions, they should be wise" (Ali, 2011: p. 75, 76).

\section{The Indigenous Worldview and the Wisdom of Hozho}

"Western civilization, unfortunately, does not link knowledge and morality but rather, it connects knowledge and power and makes them equivalent" (Vine Deloria Jr., Oglala Lakota).

Indigenous peoples are stakeholders in Western scientific endeavors (Williams \& Shipley, 2020) including the development and application of AI, both generally as citizens of an increasingly AI-permeated world and specifically as the actual subjects of AI endeavors. For example, Walker and Hamilton (2018) described using machine-learning AI applied to remote sensing data to identify uncontacted tribes in Amazonia, and reported finding three previously unknown villages using their technique. Akanbi and Masinde (2018) reported using expert-system AI as part of an early warning system for forecasting droughts based on rules derived from local Indigenous knowledge obtained from Indigenous experts. Marshall (2019) discussed an AI tool using Indigenous knowledge to better address complex environmental management problems and care for significant species and habitats, including with regard to managing invasive grass which is reducing habitat for native species. "The use of AI will support accelerated access to solutions that draw on [Indigenous peoples'] invaluable knowledge and expertise to ensure 
we build resilient and valuable environments. There is simply no substitute to that history, data, and understanding of environment over so many millennia" (Marshall, 2019). Thus, an important issue for AI is that its developers and programmers, while they may appropriate Indigenous knowledge and otherwise reduce Indigenous peoples to data, still incorporate "the same values that have fostered genocide against Indigenous people worldwide and brought us all to the brink of environmental collapse" (Lewis et al., 2018). If AI has the potential to become a new class of extremely powerful beings, then it must incorporate broad-based AW or else it will make the same mistakes as its creators but with greater efficiency, worse consequences, and less accountability (Lewis et al., 2018).

"The AI systems we develop certainly have our worldviews embedded in them. Integrating Indigenous perspectives would allow us to build a different kind of AI" (Kesserwan, 2018). For example, Bourgeois-Doyle (2019) proposed a "Two-Eyed AI" concept for guiding the development and application of AI based on the Two-Eyed Seeing principle of seeing through one eye with the best of the Indigenous way of knowing and through the other eye with the best of Western science. Maitra (2020) discussed the value of Indigenous perspectives in addressing concerns about potential negative impacts of powerful AI on human civilization, and proposed incorporating Indigenous relational ethics into AI programming in order to instill a more human-friendly foundation and thereby mitigate or avoid these negative impacts. As discussed, value alignment attempts to ensure that AI is encoded with human values in its infancy, and Indigenous ontologies, especially relational dynamics, should be considered as an extension of value alignment (Maitra, 2020). For example, as long as humans maintain a scheme in which they are superior beings using AI as means to their own ends there is a risk that AI may invert this hierarchy, so to empower and protect humans from AI, we should include AI in our "circle of relationships" and thereby create a reciprocal relationship between AI and humans (Maitra, 2020, citing Liu \& Zawieska, 2017).

Indigenous ontologies acknowledge kinship networks that extend to animals and plants, wind and rocks, mountains and oceans, and "[a]s we manufacture more machines with increasing levels of sentient-like behavior, we must consider how such entities fit within the kin-network" (Lewis et al., 2018). To that end, Kesserwan (2018) asked whether AI, such as the well-known intelligent agent Siri, would be considered an animate or an inanimate object by the Innu people of Canada. One respondent suggested that AI might be considered animate if it interacts with humans, while another suggested that it might be considered inanimate because animate nouns are limited to beings with souls (e.g., trees and rocks) (Kesserwan, 2018). Of course, the latter position requires a deeper examination of whether AI could be considered a living being with a soul, and "[b]elieving that AI has a spirit does not necessarily mean anthropomorphizing it, since being alive and having a soul does not necessarily equate to being human in Indigenous cultures" (Kesserwan, 2018, quoting Taylor, 2016). From the perspective of some Indigenous 
peoples, the question of whether AI is human is irrelevant "since Indigenous systems generally do not contain a hierarchy that privileges human life above all other life" (Kesserwan, 2018). So "[t]he fact that a lifeform is not human doesn't mean that they are not also my brother, sister, mother, father, grandmother, or grandfather" (Kesserwan, 2018, quoting Ambelin Kwaymullina).

The Indigenous worldview of the Dine (Navajo) people recognizes and honors their reciprocal responsibilities to the universe that sustains them (Haskie, 2002, citing Griffin-Pierce, 1992). "[H]armony and balance is the American Indian belief in interrelatedness and connectedness with all other animates and inanimates in the world, but it also recognizes the need for individual wellness - of the interdependence of physical, emotional, psychological, and spiritual well-being" (Haskie, 2002: p. 25, quoting Cleary \& Peacock, 1998: p. 25). "In traditional Navajo thinking, spirituality, health, harmony, and beauty are inseparable. All the good things in life - health, prosperity, happiness, and peace — are a result of living from a spiritual perspective that acknowledges all parts of the universe as alive and interdependent” (Haskie, 2002: p. 26, quoting Griffin-Pierce, 1992: p. 29).

This worldview is reflected in the concept of hozho, "a form of cultural wellness wisdom" (Kahn-John \& Koithan, 2015: p. 24) which has been characterized as the central idea in Navajo philosophy (Haskie, 2002, citing Kluckhohn, 1968). Hozho is both a way of living and a state of being, and encompasses "everything that a Navajo thinks as good - that is good as opposed to evil, favorable to man as opposed to unfavorable or doubtful" (Kahn-John \& Koithan, 2015: p. 25, quoting Wyman \& Haile, 1970). Hozho has been variously characterized as involving "harmony and good relations" (Pinto, 2000: p. 276; Haskie, 2002: p. ii); becoming/being beautiful, peaceful, harmonious, nice (Haskie, 2002, citing Young \& Morgan, 1987); "a state of much good, leading to a peaceful, beautiful, and harmonious life" (Benally, 1994: p. 23); a state of happiness and beauty in which one lives in balance (Haskie, 2002, citing Griffin-Pierce, 1992); and a "positive or ideal environment [of] beauty, harmony, good, happiness, and everything that is positive [and] all-inclusive" (Haskie, 2002: pp. 27-28, citing Witherspoon, 1974). “At the same time, hozho is a highly complex concept, and it cannot be explained in one simple definition ... [I]ndividuals can spend their entire lifetime trying to achieve that state of hozho" (Haskie, 2002: pp. 27-28).

Honoring relationships is fundamental, and to live in hozho requires a constant awareness of the relationships and interconnectedness between the individual and the environment ("others," e.g., family, community, tribe, spirits, people of the world, all living creatures, nature, and the universe) (Kahn-John \& Koithan, 2015). "Hozho teaches that respectful thought, speech, and behavior should be nurtured and relationships in life, including those with the whole of creation in the universe, should be supportive and positive" (Kahn-John \& Koithan, 2015: p. 25). Hozho is a process, path, or journey by which an individual strives "to achieve that delicate balance, one that is pursued with the person ever mindful about the existence of forces, both positive and negative. 'The all-inclusive nature 
of the universe means that all forces are integrated, good and evil, natural and supernatural, male and female, into a state of balance and harmony"' (Haskie, 2002: p. 28, 29, quoting Griffin-Pierce, 1992: p. 35). Hozho includes principles that guide thoughts, actions, behaviors, and speech (Kahn-John \& Koithan, 2015; Wyman \& Haile, 1970). People who consistently model hozho have been characterized as humble; intelligent; patient; respectful and thoughtful; soft spoken; good and attentive listeners; disciplined and hardworking; generous; supportive, caring, and empathetic; positive in thought, speech, and behaviors; spiritual; loyal and reliable; honest; creative and artistic; peaceful and harmonious; perceptive, understanding, and wise; confident; calm; deliberate in actions; gentle yet firm; and self-controlled (Kahn-John \& Koithan, 2015, citing Mitchell, 1978, and Holiday \& McPherson, 2005). Dine elders are the ideal role models for hozho, having both received its ancient teachings and having had a lifetime of experience in working toward attaining it (Kahn-John \& Koithan, 2015, citing Mitchell, 1978, and Holiday \& McPherson, 2005).

Many Indigenous peoples have concepts similar to hozho which recognize how humans are an equal and integral part of local ecologies rather than being related merely as subject and object (Irwin \& White, 2019). For example, in Lakota relational ontology there is the concept of mitakuye oyasin ("everything is related") and there arises a "sense of responsibility [or kinship] toward every individual dealt with,' including humans and non-humans" (Maitra, 2020: p. 324, citing Hughes, 1996 and quoting Deloria, 1998). Maori philosophy also includes a taxonomy of relationships defined as a genealogy of connection, or whakapapa, in which humans are one species embedded in a network of familial relations with ecological place (Irwin \& White, 2019). Brown discussed the "Iwi Algorithm" which seeks to embed Maori cultural values in AI decision-making and thereby learn from the past to inform the technology that will define the future (Brown, 2019).

\section{Example Applications}

The issue of AW is particularly salient with regard to "big data" resulting from the proliferation of electronic records and smart devices which have made large amounts of data increasingly easier and cheaper to collect, process, and analyze (Car et al., 2019). "Data must be transformed before it can be useful," and implementation science is the study of methods for promoting the systematic uptake of research findings and other evidence-based practices into routine practice (Car et al., 2019: p. 143). A commonly used framework employs the data, information, knowledge, and wisdom (DIKW) hierarchy (Car et al., 2019, citing Zeleny, 1987 and Ackoff, 1989).

For example, in the context of healthcare, Powell (2019) distinguished "data-facing" applications for AI involving data processing and "user-facing" applications involving interaction with patients. With regard to the latter, Powell (2019: p. 1,2) argued that "many medical decisions require value judgements and the 
doctor-patient relationship requires empathy and understanding to arrive at a shared decision ... Arguably, medicine requires wisdom more than intelligence, artificial or otherwise ... and we are a long way away from a science of artificial wisdom." Similarly, Car et al. (2019: p. 143) noted in their discussion of the difficulty of applying big data to healthcare, that "[d] espite the apparent enthusiasm of researchers, funders, and the media, evidence is scarce for successful implementation of products, algorithms, and services arising that make a real difference to clinical care ... [O]nly a tiny fraction of research ever translates into routine clinical care". However, this may be a result of a narrow Western approach to the problem. As Kahn-John and Koithan (2015: p. 26) noted, "Hozho aligns with the meta-theoretical beliefs, values, and principles of integrative nursing," so incorporating hozho into AW could enhance the usefulness of and overall benefit from applications of AI to healthcare.

Similarly, in the context of law, Pocker (2018: p. 4) noted that "[j]udgment and discretion are the key strengths of our justice system, and both require the human attributes of compassion, wisdom, experience, and intuition," and predicted that artificial judgment, artificial wisdom, and artificial justice would never be developed. Doing justice is not a matter of having enough data, and the most historically influential decisions could not have been outputted by an algorithm (Pocker, 2018). "Every time we have surrendered some portion of the adjudicatory process to formulas or technology, the byproducts have been expensive, exclusionary or controversial" (Pocker, 2018: p. 5). In the Navajo legal philosophy and justice system of beehaz'aannii ("the source of a healthy and happy life"), which teaches that everyone and everything is connected, a naat'aanii ("peacemaker") attempts to resolve conflicts between community members in a way that restores harmony between the parties and heals everyone involved (Yazzie, 1994). The ultimate goal of this process is hozho nahasdlii ("now that we have done these things we are again in good relations") (Yazzie, 1996). Thus, incorporating hozho into AW could also enhance the usefulness of and overall benefit from applications of AI to law.

\section{Conclusion}

The current narrow or weak form of AI is, by itself, a data analysis tool that does nothing more or less than its programming instructs it to do. AI excels at sensing its environment and acting to maximize the likelihood of achieving its goals. However, it has no values or goals of its own, it simply follows the values and pursues the goals provided to it by its programmers. AW has the potential to make $\mathrm{AI}$ at least a better tool and perhaps, eventually, more than a tool, but at least for now, AW must also be programmed and therefore similarly reflects only the wisdom of its programmers. Unlike intelligence, wisdom has a normative aspect, particularly with regard to whether and how a goal ought to be pursued, and no amount of descriptive data, by itself, can determine what ought to be done. It is not enough to recognize that AI must provide social benefit, align with our values, 
and, more generally, perform wisely without understanding that what constitutes social benefit, values, and wisdom is not universal but rather varies for different worldviews.

Without a conscious effort to incorporate the wisdom of other cultures, AW will continue to reflect one, narrow worldview. Different cultures have different notions of wisdom, and AW would benefit greatly from incorporating elements of non-Western worldviews, particularly the metaphysically inclusive worldviews of Indigenous peoples who are also stakeholders in the development and application of AI. For example, incorporating aspects of the Navajo concept of hozho into AW could greatly enhance the usefulness of overall benefit from applications of AI. Hozho introduces the values and goals of harmony, balance, interrelatedness, and connectedness, and thereby has the potential to elevate AI beyond the technoscientific foundation of the Western scientific worldview which has created so many of our past and present problems.

\section{Acknowledgements}

The authors are grateful to Hovey Williams LLP for its generous support of science and innovation.

\section{Conflicts of Interest}

The authors declare no conflicts of interest regarding the publication of this paper.

\section{References}

Ackoff, R. L. (1989). From Data to Wisdom. Journal of Applied Systems Analysis, 16, 3-9.

Akanbi, A. K., \& Masinde, M. (2018). Towards the Development of a Rule-Based Drought Early Warning Expert Systems Using Indigenous Knowledge. 2018 International Conference on Advances in Big Data, Computing and Data Communication Systems (icABCD). https://ieeexplore.ieee.org/document/8465465 https://doi.org/10.1109/ICABCD.2018.8465465

Ali, A. Z. (2011). A Philosophical Approach to Artificial Intelligence and Islamic Values. International Islamic University Malaysia Engineering Journal: Special Issue in Science and Ethics, 12, 73-78.

Ardelt, M. (2004). Wisdom as Expert Knowledge System: A Critical Review of a Contemporary Operationalization of an Ancient Concept. Human Development, 47, 257-285. https://doi.org/10.1159/000079154

Baltes, P. B., \& Smith, J. (2008). The Fascination of Wisdom: Its Nature, Ontogeny, and Function. Perspectives on Psychological Science, 3, 56-64. https://doi.org/10.1111/j.1745-6916.2008.00062.x

Baltes, P. B., \& Staudinger, U. M. (2000). Wisdom: A Metaheuristic (Pragmatic) to Orchestrate Mind and Virtue toward Excellence. American Psychologist, 55, 122-136. https://doi.org/10.1037/0003-066X.55.1.122

Bell, G. (2017). Putting AI in Its Place: Why Culture, Context and Country Still Matter. http://www.youtube.com/watch?v=WBHG4eBeMXk

Benally, H. (1994). Navajo Philosophy of Learning and Pedagogy. Journal of Navajo Education, 12, 23-31.

Bourgeois-Doyle, D. (2019). Two-Eyed AI: A Reflection on Artificial Intelligence. https://www.google.com/url?sa=t\&rct=j\&q=\&esrc=s\&source=web\&cd=\&ved=2ahUKE 
wi52KaK47nrAhWJQc0KHdBQCtsQFjABegQICxAD\&url=https\%3A\%2F\%2Fen.ccun

es-

co.ca\%2F-\%2Fmedia\%2FFiles $\% 2$ FUnesco $\% 2$ FResources $\% 2$ F2019\%2F03\%2FTwoEye dArtificialIntelligence.pdf\&usg=AOvVaw1fKHwXg3SQGSaQGQ3FjTkg

Braga, A., \& Logan, R. K. (2017). The Emperor of Strong AI Has No Clothes: Limits to Artificial Intelligence. Information, 8, 156. https://doi.org/10.3390/info8040156

Brown, R. (2019). Artificial Indigenous Intelligence: Putting Te Ao Mãori at the Centre of Tech.

https://thespinoff.co.nz/partner/microsoft/20-08-2019/artificial-indigenous-intelligence-p utting-te-ao-maori-at-the-centre-of-tech

Car, J., Sheikh, A., Wicks, P., \& Williams, M. S. (2019). Beyond the Hype of Big Data and Artificial Intelligence: Building Foundations for Knowledge and Wisdom. BMC Medicine, 17, 143. https://doi.org/10.1186/s12916-019-1382-x

Cleary, L. M., \& Peacock, T. D. (1998). Collected Wisdom: American Indian Education. Boston, MA: Allyn \& Bacon.

Davis, J. P. (2019). Lawyering in the Age of Artificial Intelligence: Artificial Wisdom? A Potential Limit on AI in Law (and Elsewhere). Oklahoma Law Review, 72, 51-89. https://doi.org/10.2139/ssrn.3350600

Deloria, E. C. (1998). Speaking of Indians. Lincoln, NB: University of Nebraska Press.

Grieg, R. J., \& Zimbardo, P. G. (2003). Psychology and Life (Chinese Edition, L. Wang, Trans.). Beijing: Posts \& Telecom Press.

Griffin-Pierce, T. (1992). Earth Is My Mother, Sky Is My Father: Space, Time, and Astronomy in Navajo Sandpainting. Albuquerque, NM: University of New Mexico Press.

Haskie, M. J. (2002). Preserving Culture: Practicing the Navajo Principles of Hozho Doo K'e. Dissertation, UMI No. 3077247, Ann Arbor, MI: Proquest.

Holiday, J., \& McPherson, R. S. (2005). A Navajo Legacy: The Life and Teachings of John Holiday. Norman, OK: University of Oklahoma Press.

Hughes, J. D. (1996). North American Indian Ecology. El Paso, TX: Texas Western Press.

Irwin, R., \& White, T. H. (2019). Decolonising Technological Futures: A Dialogical Tryptich between Te Haumoana White, Ruth Irwin, and Tegmark's Artificial Intelligence. Futures, 112, Article ID: 102431. https://doi.org/10.1016/j.futures.2019.06.003

Kahn-John, M., \& Koithan, M. (2015). Living in Health, Harmony, and Beauty: The Diné (Navajo) Hózhó Wellness Philosophy. Global Advances in Health and Medicine Journal, 4, 24-30. https://doi.org/10.7453/gahmj.2015.044

Kaplan, A., \& Haenlein, M. (2019). Siri, Siri, in My Hand: Who's the Fairest in the Land? On the Interpretations, Illustrations, and Implications of Artificial Intelligence. Business Horizons, 62, 15-25. https://doi.org/10.1016/j.bushor.2018.08.004

Kesserwan, K. (2018). How Can Indigenous Knowledge Shape Our View of AI? https://policyoptions.irpp.org/magazines/february-2018/how-can-indigenous-knowledgeshape-our-view-of-ai

Kim, T. W., \& Mejia, S. (2019). From Artificial Intelligence to Artificial Wisdom: What Socrates Teaches Us. Computer, 52, 70-74. https://doi.org/10.1109/MC.2019.2929723

Kim, T. W., Donaldson, T., \& Hooker, J. (2018). Mimetic vs Anchored Value Alignment in Artificial Intelligence. https://arxiv.org/abs/1810.11116

Kluckhohn, C. K. M. (1968). The Philosophy of the Navajo Indians. In M. H. Fried (Ed.), Readings in Anthropology (pp. 674-699). New York: Thomas Y. Crowell.

Legg, S., \& Hutter, M. (2007). A Collection of Definitions of Intelligence. https://arxiv.org/pdf/0706.3639.pdf

Lewis, J. E., Arista, N., Pechawis, A., \& Kite, S. (2018). Making Kin with the Machines. https://doi.org/10.21428/bfafd97b

Liu, H.-Y., \& Zawieska, K. (2017). From Responsible Robotics towards a Human Rights Regime Oriented to the Challenges of Robotics and Artificial Intelligence. Ethics and Information Technology, 24, 1-13. https://doi.org/10.1007/s10676-017-9443-3

Maitra, S. (2020). Artificial Intelligence and Indigenous Perspectives: Protecting and Empowering Intelligent Human Beings. Proceedings of the 2020 Artificial Intelligence and 
Ethics Society Conference (AIES'20), New York, February 2020, 320-326. https://doi.org/10.1145/3375627.3375845

Marshall, L. (2019). AI + Indigenous Knowledge a Powerful Tool Posing Critical Questions.

https://algorithm.data61.csiro.au/ai-indigenous-knowledge-a-powerful-tool-posing-critica $\underline{\text { l-questions }}$

McLaughlin, L. (2012). Enterprise 2.0: Uncomfortable Truths about Big Data. https://www.informationweek.com/enterprise-20-uncomfortable-truths-about-big-data/d/ d-id/1104947

Miguel, R. S. S. (2002). A New Concept of Knowledge. Online Information Review, 26, 239. https://doi.org/10.1108/14684520210438688

Mitchell, F. (1978). Navajo Blessing Way Singer: The Autobiography of Frank Mitchell, 1881-1967. Tucson, AZ: University of Arizona Press.

Pinto, J. (2000). Peacemaking as Ceremony: The Mediation Model of the Navajo Nation. The International Journal of Conflict Management, 11, 267-286.

Pocker, R. (2018). Artificial Wisdom. Nevada Lawyer, 26, 4-5.

Poole, D., Mackworth, A., \& Goebel, R. (1998). Computational Intelligence: A Logical Approach. New York: Oxford University Press.

Powell, J. (2019). Trust Me, I'm a Chatbot: How Artificial Intelligence in Health Care Fails the Turing Test. Journal of Medical Internet Research, 21, e16222. https://doi.org/10.2196/16222

Russell, S. J., \& Norvig, P. (2003). Artificial Intelligence: A Modern Approach (2nd ed.). Upper Saddle River, NJ: Prentice Hall.

Russell, S., Dewey, D., \& Tegmark, M. (2015). Research Priorities for Robust and Beneficial Artificial Intelligence. AI Magazine, Winter, 105-115. https://doi.org/10.1609/aimag.v36i4.2577

Sevilla, D. C. (2013). The Quest for Artificial Wisdom. AI \& Society, 28, 199-207. https://doi.org/10.1007/s00146-012-0390-6

Shipley, G. P., \& Williams, D. H. (2019). Limitations of the Western Scientific Worldview for the Study of Metaphysically Inclusive Peoples. Open Journal of Philosophy, 9, 295-317. https://doi.org/10.4236/ojpp.2019.93020

Singer, D. J. (2015). Mind the Is-Ought Gap. The Journal of Philosophy, 112, 193-210. https://doi.org/10.5840/jphil2015112412

Sternberg, R. J. (2004). Words to the Wise about Wisdom? A Commentary on Ardelt's Critique of Baltes. Human Development, 47, 286-289. https://doi.org/10.1159/000079155

Taylor, D. H. (2016). Take Us to Your Chief. Vancouver: Douglas \& McIntyre.

Walker, R. S., \& Hamilton, M. J. (2018). Machine Learning with Remote Sensing Data to Locate Uncontacted Indigenous Villages in Amazonia. https://doi.org/10.7287/peerj.preprints.27307v1

Wang, F., \& Zheng, H. (2012). A New Theory of Wisdom: Integrating Intelligence and Morality. Psychology Research, 2, 64-75. https://doi.org/10.17265/2159-5542/2012.01.007

Weidenbener, L. (2019). Many Questions, Fewer Answers at Intersection of AI, Ethics. Indianapolis Business Journal, 40, 20-21.

Williams, D. H., \& Shipley, G. P. (2020). Scientific Consequentialism: Potential Problems with an Outcome-Driven Form of Indigenous Archaeology. Archaeological Discovery, 8, 63-83. https://doi.org/10.4236/ad.2020.81004

Wilson, E. O. (1998). Consilience: The Unity of Knowledge. New York, NY: Alfred A. Knopf.

Witherspoon, G. (1974). The Central Concepts of Navajo World View, I. Linguistics, 119, 41-59. https://doi.org/10.1515/ling.1974.12.119.41

Wu, M., \& Wu, X. (2019). On Big Wisdom. Knowledge and Information Systems, 58, 1-8. https://doi.org/10.1007/s10115-018-1282-y

Wyman, L. C., \& Haile, B. (1970). Blessingwav. Tucson, AZ: University of Arizona Press. 
Yazzie, R. (1994). Life Comes From It: Navajo Justice.

https://www.context.org/iclib/ic38/yazzie

Yazzie, R. (1996). "Hozho Nahasdlii”-We Are Now in Good Relations: Navajo Restorative Justice. St. Thomas Law Review, 9, 117-124.

Young, R. W., \& Morgan, W. (1987). The Navajo Language: A Grammar and Colloquial Dictionary. Albuquerque, NM: University of New Mexico Press.

Zeleny, M. (1987). Management Support Systems: Towards Integrated Knowledge Management. Human Systems Management, 7, 59-70.

https://doi.org/10.3233/HSM-1987-7108 